\title{
Household relationships and healthcare seeking behaviour for common childhood illnesses in sub-Saharan Africa: a cross- national mixed effects analysis
}

Joshua O. Akinyemi ${ }^{1,2^{*}}$ (D, Pamela Banda ${ }^{1}$, Nicole De Wet ${ }^{1}$, Adenike E. Akosile ${ }^{1,3}$ and Clifford O. Odimegwu ${ }^{1}$

\begin{abstract}
Background: Intra-household dynamics play crucial roles in utilisation of healthcare services for children. We investigated the influence of household relationships on healthcare seeking behaviour for common childhood illnesses in four sub-Sahara African regions.

Methods: Data on 247,061 under-five children were extracted from recent Demographic and Health Surveys conducted between 2012 and 2016 in 25 countries. Data were combined and analysed per sub-region. Dependent variables (DVs) were uptake of health facility care for diarrhea and Acute Respiratory Tract Infection (ARI) symptoms. The main independent variable (IV) was household relationship which was represented by maternal marital profile (marital status, family type and number of marriages) and maternal relationship to household head. Mixed effects logit models were fitted to assess independent relationship between the IVs and DVs with adjustment for relevant demographic and socio-economic characteristics at 5\% significance level.

Results: The percentage of children who received care for diarrhea and ARI symptoms from health facilities across sub-regions was: Western Africa (WA) 42.4, 44.1\%; Central Africa (CA) 32.6, 33.9\%; Eastern Africa (EA) 41.5, 48.7\% and Southern Africa (SA) 58.9, 62.7\%. Maternal marital profile was not associated with healthcare seeking behaviour for diarrhea and ARI symptoms in any of the sub-regions. Children whose mothers were daughter/daughter-in-law to household head were significantly less likely to be taken to health facility for diarrhea treatment in Eastern Africa $(A O R=0.81, \mathrm{Cl}: 0.51-0.95)$. Having a mother who is the head of household was significantly associated with higher odds of facility care for ARI symptoms for children from Western (AOR =1.20, Cl: 1.02-1.43) and Southern Africa $(\mathrm{AOR}=1.49, \mathrm{Cl}: 1.20-1.85)$.

Conclusion: The type of relationship between mother of under-fives and head of households affect health seeking behaviour for treatment of diarrhea and ARI symptoms in Eastern, Western and Southern Africa. Countries in these regions need to adapt best practices for promoting healthcare utilisation for children such that household relationship does not constitute barriers.
\end{abstract}

Keywords: Family context, Household relationships, Childhood illnesses, Healthcare seeking behaviour, Healthcare utilisation, Sub-Saharan Africa

\footnotetext{
* Correspondence: odunjoshua@gmail.com

${ }^{1}$ Demography and Population Studies Programme, Schools of Public Health and Social Sciences, University of the Witwatersrand, Johannesburg, South Africa

${ }^{2}$ Department of Epidemiology and Medical Statistics, Faculty of Public Health, College of Medicine, University of Ibadan, Ibadan, Nigeria

Full list of author information is available at the end of the article
}

(c) The Author(s). 2019 Open Access This article is distributed under the terms of the Creative Commons Attribution 4.0 International License (http://creativecommons.org/licenses/by/4.0/), which permits unrestricted use, distribution, and reproduction in any medium, provided you give appropriate credit to the original author(s) and the source, provide a link to the Creative Commons license, and indicate if changes were made. The Creative Commons Public Domain Dedication waiver (http://creativecommons.org/publicdomain/zero/1.0/) applies to the data made available in this article, unless otherwise stated. 


\section{Background}

Though there has been steady progress in reduction of childhood deaths from infectious causes, the magnitude is still substantial in sub-Saharan Africa region. Approximately, $50 \%$ of global under-five deaths were from the region [1]. Globally, half of childhood deaths are due to infections - with pneumonia, diarrhea and measles leading the trail $[1,2]$. Fortunately, these conditions are both preventable and treatable. The recommended point of care and treatment for childhood illnesses is health facility [3]. A persistent challenge in sub-Saharan Africa and many other developing regions is poor healthcare seeking behaviour despite availability of effective treatments for childhood diseases. According to findings from a systematic review, care-seeking from community health workers for diarrhoea, pneumonia and malaria was very low in developing countries [3].

Meanwhile, the second target under the third Sustainable Development Goal (SDG 3) is aimed at ending preventable neonatal and under-five deaths by the year 2030. For this goal to be achieved, efforts need to be geared towards improving healthcare seeking behaviour for childhood illnesses. In poor resource settings such as those found in many sub-Saharan Africa communities, household relationships constitute a challenge to healthcare utilisation. Household relationships are not static; they are subject to the prevailing socio-economic and development ecosystem in different countries [4-6]. Similarly, the effect of household relationships on healthcare seeking behaviour is transient in nature, thereby necessitating occasional re-appraisal [6-8].

Literature has shown that childhood mortality, morbidity, and healthcare seeking behaviour share similarities in terms of associated factors [9-12] in which socio-economic and demographic variables are prominent. Women with secondary or higher education and those living in rich households are more likely to seek appropriate care when their children are ill compared to those with no formal education and those from poor households [13-15], respectively. Likewise, urban dwellers seek appropriate care more than those in rural areas $[16,17]$. Meanwhile, demographic variables often found related to healthcare access include age of child and number of under-five children in the household. Children aged below 2 years enjoyed better care-seeking $[14,15,18]$ while the number of under-fives in the household is negatively associated with healthcare seeking behaviour [16, 19]. Decision-making power, access to and control over economic resources by mothers of under-five children have also been reported to positively influence care-seeking for childhood illnesses [20, 21]. Distance to health facilities and inability to raise money to pay for cost of treatment are other barriers that have been identified by past studies $[18,19,22]$. Beyond the aforementioned factors, another important social determinant of children health is the family/household environment which includes features such as family structure, social support and intra-household relationships [23]. With research suggesting that access to health is multidimensional [24], analytical studies are needed to investigate other variables such as social structure, family and community characteristics.

Some previous studies, mostly qualitative in design, have shown evidence to underscore the importance of the family environment in care-seeking for childhood illnesses [25-28]. Two main revelations emerged from these qualitative studies. First, decision to seek appropriate health care for a sick child depends on the household's social context, social structure, social networks and support within the family [21, 27-29]. Second, there is existence of relationship dynamics especially between a mother and the household head. Father's presence or absence and/or his disposition to the mother determine whether or not a sick child is taken to health facility for treatment $[21,25,27,30]$. The influence of these intra-household dynamics needs to be investigated on a larger scale.

In this study, we explored these issues using available nationally representative survey data in sub-Saharan Africa, bearing in mind the diversities across different sub-regions. Further investigation of factors affecting care-seeking behaviour for childhood illnesses is imperative for two reasons. First, the roles of families and communities remain central as seen in the strategic revision to the World Health Organisation's (WHO) guidelines on Integrated Management of Neonatal and Childhood Illnesses [31]. Two, the topmost research priority identified as having potential to reduce childhood deaths from pneumonia (treatable but a leading cause of childhood mortality) is investigation of barriers to healthcare access [32]. In view of these imperatives, we investigated the influence of household relationship on healthcare seeking behaviour for childhood illnesses in sub-Saharan Africa. Of the three common childhood illnesses, the topmost two - diarrhea and ARI symptoms were selected. Besides, information about them is readily available from household surveys. We hypothesized that the relationship between mother of under-five and the household head affects care-seeking behaviour for diarrhea and ARI symptoms.

\section{Methods}

This study involved secondary analysis of cross-sectional data extracted from the most recent Demographic and Health Surveys (DHS) conducted in 25 sub-Saharan African countries between 2012 and 2016 (Additional file 1: Table S1). The DHS data are nationally representative 
household surveys conducted in several developing countries since the late 1990s [33]. The surveys cover several topics related to population health of which maternal and child health is prominent. Men and women (both aged 1559 years old) are usually selected for interview via stratified two-stage cluster sampling technique. The primary sampling units are census enumeration areas (EAs). These EAs are stratified by rural and urban localities. The first stage of sampling is selection of specified number of EAs in rural and urban localities. In selected EAs, household listing and numbering is done to generate sampling frame for second stage of sampling. Depending on the sample size required, a fixed number of households are subsequently selected using a systematic sampling with probability proportional to size (number of households) of the EAs. Variables and data collection methodologies are standardized across countries and surveys thus facilitating multi-country analyses [34]. Data on all children ever born to women were collected in the reproductive history section of the women's questionnaire. Additional data on health and anthropometry characteristics of children alive at the time of survey were also collected. Data were collected using standardized questionnaire by trained field workers. In this study, we analysed data for a weighted sample of 247,061 children who were alive during the surveys. Though the data analysed covered an average of 5-year period, this time interval is narrow and did not affect the overall findings of the study.

\section{Theoretical framework}

For theoretical foundation, we adapted the phase 5 model of health services use [35]. The model which was first proposed in the late 1960s has been applied in several studies of healthcare utilisation and has been reviewed five times to capture the complex nature of factors related to health-seeking behaviour [35, 36]. In the most recent version, environmental or contextual factors and population characteristics were argued to influence the use of health services. Environmental factors include healthcare system, resources, social and economic development. Population characteristics were represented by demographics, family social structure and community characteristics. In this study, a sub-component of the relationships hypothesized in the model is empirically investigated by focusing on some components under population characteristics and their effect on healthcare seeking behaviour for childhood illnesses.

\section{Variables}

Two dependent variables were analysed and these are healthcare seeking behaviour for diarrhea and Acute Respiratory Tract Infection (ARI) symptoms. The variables were dichotomous, coded Good [1] and Poor (0). In this study, good healthcare seeking behaviour refers to public or private health facility visit to access care for diarrhea or ARI symptoms. Care-seeking for diarrhea was derived from three set of questions under the child immunisation, health and nutrition section of the DHS women's questionnaire. The first question was "Has child had diarrhea in the last 2 weeks". If mother answered "Yes", she was asked the second question - "Did you seek advice or treatment for the diarrhea from any source". With an affirmative response to the second question, the interviewer proceeded to the third one - "where did you seek advice or treatment".

Care-seeking for ARI symptoms was derived in similar manner to diarrhea. The first question posed to a mother was "Has child had an illness with a cough at any time in the last 2 weeks?" If mother answered 'Yes', she was further asked "When child had an illness with a cough, did he/she breath faster than usual with short, rapid breaths or have difficulty breathing?". Children for whom the answer to these two questions was 'Yes' were categorised as having ARI symptoms. The third and fourth question which relate to care-seeking was "Did you seek advice or treatment for the illness from any source?" and "where did you seek advice or treatment?"

Two explanatory variables were employed to represent household relationships. These were maternal marital profile and relationship to household head. Maternal marital profile has six categories that captured the marital status, family type and number of marriages a mother has had. The categories were: 1 - never married; 2 - first order monogamy, 3- first order polygyny, 4- higher order monogamy, 5- higher order polygyny and 6formerly married (separated, divorced or widowed). Order of a marriage is the number of times a woman has been married. Therefore, first order means that a woman has been married only once while higher order implied being married two or more times. Monogamy is the situation whereby a woman report that her partner do not have other wives while polygyny implied that there are other co-wives. Relationship between the mother of under-five and household head was categorised as 1-head of household (that is the mother is also the household head), 2- wife, 3- daughter or daughter-in-law and 4- others.

Based on existing literature, we adjusted for other background variables representing the demographic and socio-economic characteristics of the mother and household $[14,16,37]$. These were maternal education, maternal age, occupation, household wealth index, place of residence, sex of child, age of child, birth order, and number of under-five children in the household.

\section{Statistical analysis}

Analysis was done for sub-Saharan Africa as a whole and for each sub-region [Western Africa; Central Africa; 
Eastern Africa; Southern Africa]. To provide a description of the study variables, weighted percentage distributions were estimated. In order to account for the complex sampling scheme employed in the DHSs and the hierarchical structure of the data, three-level mixed effects logit models were fitted to explore the independent association between household relationships and healthcare seeking behaviour for diarrhea and ARI symptoms. In this study, children-mother pairs were nested in clusters or communities (primary sampling unit) which were in turn nested within countries. Thus, for the three-level mixed effects model, mother-child pairs represents level 1 , clusters are level 2 , while countries represent level 3. Estimation models for each sub-region were based on the equation below:

$$
\log _{e}\left[\frac{p_{i j k}}{1-p_{i j k}}\right]=X_{i j k}+\mu_{j k}+v_{k}
$$

Where:

$P_{i j k}=$ probability of good healthcare seeking behaviour by mother-child pair $i$, in community $j$ and country $k$.

$X_{i j k}=$ vector of explanatory variables.

$\beta=$ regression coefficient representing effects of respective explanatory variable on probability of good health seeking behaviour.

$\mu_{\mathrm{jk}}=$ community-level variance.

$v_{k}=$ country-level variance.

Models were fitted in two stages. In the first model, each of the variables for household relationship was used to estimate unadjusted effects. Thereafter, to obtain adjusted effects, demographic and socio-economic variables were added to the model. We did not use any variable selection technique because we were interested in an explanatory rather than a predictive model. The explanatory model was aimed at clarifying the independent association between household relationship and healthcare seeking behaviour.

Mixed effects models have two components - random and fixed. Random effects were estimated at cluster (community) and country levels. Fixed effects of explanatory variables were estimated as Adjusted Odds Ratio (AOR) with 95\% Confidence Interval (CI). Model fitness was assessed and all anayses were conducted using Stata MP version 14 .

\section{Results}

\section{Healthcare seeking behaviour for diarrhea}

Of a weighted sample of 247,061 under-five children, 36,865 (14.9\%) were reported to have had diarrhea and 23,135 (9.4\%), ARI symptom. Healthcare seeking behaviour is presented in Table 1 with left panel for diarrhea and right panel for ARI symptoms. By region, the percentage of children whose mothers sought treatment for diarrhea from health facility was: Western Africa (WA)- 42.4\%, Central Africa (CA) - 32.6\%, Eastern Africa (EA) - 41.5\% and
Southern Africa (SA) - 58.9\%. Health facility care for diarrhea was almost evenly distributed according to maternal age except for those aged 40 years and above who were slightly lower than the other age groups. Educational gaps were observed in WA, CA, and EA where facility care for diarrhea was more common in children whose mothers had secondary/higher education than those with no formal education. In WA, 35.3 and $47.9 \%$ of under-five children in poorest and richest household respectively received facility care for diarrhea, while 27.7 and $38.8 \%$ respectively for CA. There were no such differentials in EA and SA sub-regions. Similarly, seeking of health facility care for diarrhea was slightly more common in urban compared to rural areas in WA and CA, unlike the other two sub-regions where no such disparity was observed.

In terms of household relationship (Table 2, left panel), children of women in polygynous households recorded poorer visit of health facility for diarrhea treatment in WA and CA whereas first and higher order monogamy had the poorest uptake in EA. For SA sub-region, no major differential was observed; however children of never married women $(63.0 \%)$ had the highest utilisation of health facility while higher order polygyny and first order monogamy had 56.2 and $59.2 \%$ respectively. Children of women who were wives to head of household (40.1\%) had the lowest utilisation of health facility for diarrhea treatment in WA whereas the lowest in CA was among children whose mothers were household heads (30.7\%) and among children whose mothers were daughter or daughter-in-law to household head in EA.

\section{Healthcare seeking behaviour for ARI symptoms}

Among children with ARI symptoms, the percentage for whom care was sought from health facility across the four sub-regions was: WA - 44.1\%; CA - 33.9\%; EA - 48.7\%; SA $-62.7 \%$ (Table 1, right panel). The percentage did not vary by maternal age but educational differentials were observed in WA, CA and EA where children whose mothers had secondary/higher education had the highest rates of health facility utilisation. Table 1 (right panel) also showed that health facility care-seeking for ARI symptoms was more common among children with working (66.1\%) than non-working mother $(58.1 \%)$ in SA. The widest wealth differential was observed in WA between the poorest (37.3\%) and richest households $(52.9 \%)$ which was closely followed by CA (poorest $-26.6 \%$, richest $-45.2 \%$ ) and EA (poorest - 46.6\%, richest $-54.8 \%$ ). Care-seeking for ARI symptoms in SA was very close between the poorest $(61.1 \%)$ and richest (66.2\%) households. The percentage for whom healthcare was sought from health facility was lower among children in rural areas in WA (rural - 41\%, urban - 50.6\%) and CA (rural - 28.5\%, urban - 43.2\%). Rural-urban differential was nearly absent in EA and SA. 
Table 1 Demographic and socio-economic characteristics of mothers of under-five children who sought care for diarrhea and ARI symptoms from health facilities in sub-Saharan Africa, 2012-2016

\begin{tabular}{|c|c|c|c|c|c|c|c|c|c|c|}
\hline & \multicolumn{5}{|c|}{ Health facility care for diarrhea } & \multicolumn{5}{|c|}{ Health facility care for ARI symptoms } \\
\hline & $\begin{array}{l}\text { Western } \\
\text { Africa }\end{array}$ & $\begin{array}{l}\text { Central } \\
\text { Africa }\end{array}$ & $\begin{array}{l}\text { Eastern } \\
\text { Africa }\end{array}$ & $\begin{array}{l}\text { Southern } \\
\text { Africa }\end{array}$ & $\begin{array}{l}\text { sub-Saharan } \\
\text { Africa }\end{array}$ & $\begin{array}{l}\text { Western } \\
\text { Africa }\end{array}$ & $\begin{array}{l}\text { Central } \\
\text { Africa }\end{array}$ & $\begin{array}{l}\text { Eastern } \\
\text { Africa }\end{array}$ & $\begin{array}{l}\text { Southern } \\
\text { Africa }\end{array}$ & $\begin{array}{l}\text { sub-Saharan } \\
\text { Africa }\end{array}$ \\
\hline \multicolumn{11}{|c|}{ Maternal age (years) } \\
\hline$<20$ & 42.0 & 35.6 & 37.5 & 60.7 & 44.7 & 46.7 & 35.9 & 46.7 & 63.2 & 47.2 \\
\hline $20-29$ & 42.6 & 32.5 & 42.2 & 59.2 & 43.8 & 44.0 & 34.5 & 50.1 & 63.5 & 46.8 \\
\hline $30-39$ & 43.0 & 32.9 & 42.3 & 57.6 & 43.3 & 44.2 & 33.4 & 48.2 & 61.6 & 45.7 \\
\hline$>=40$ & 39.2 & 27.6 & 37.2 & 58.7 & 39.3 & 42.6 & 30.0 & 42.5 & 60.3 & 42.4 \\
\hline \multicolumn{11}{|c|}{ Maternal education } \\
\hline None & 40.5 & 25.3 & 39.7 & 53.8 & 38.0 & 41.3 & 22.4 & 39.2 & 62.2 & 37.9 \\
\hline Primary & 42.2 & 33.3 & 39.8 & 60.9 & 45.7 & 42.0 & 33.3 & 46.9 & 61.8 & 46.9 \\
\hline $\begin{array}{l}\text { Secondary/ } \\
\text { higher }\end{array}$ & 48.8 & 38.5 & 47.4 & 57.0 & 47.8 & 54.0 & 44.7 & 57.3 & 64.0 & 54.5 \\
\hline \multicolumn{11}{|c|}{ Employment status } \\
\hline Working & 41.6 & 33.7 & 33.6 & 60.3 & 42.3 & 44.2 & 34.6 & 42.8 & 66.1 & 45.6 \\
\hline Not working & 43.7 & 31.2 & 40.8 & 56.9 & 43.4 & 44.0 & 33.0 & 48.2 & 58.1 & 44.9 \\
\hline \multicolumn{11}{|c|}{ Household wealth quintile } \\
\hline Poorest & 35.3 & 27.7 & 44.9 & 57.9 & 40.0 & 37.3 & 26.6 & 46.6 & 61.1 & 41.6 \\
\hline Poor & 41.5 & 31.9 & 42.0 & 58.1 & 42.9 & 39.5 & 32.7 & 50.3 & 59.5 & 44.1 \\
\hline Middle & 43.8 & 32.3 & 41.5 & 61.2 & 44.2 & 45.5 & 32.6 & 44.9 & 64.9 & 45.9 \\
\hline Richer & 46.7 & 34.0 & 39.4 & 60.1 & 45.4 & 48.2 & 36.1 & 48.7 & 63.5 & 48.2 \\
\hline Richest & 47.9 & 38.8 & 37.6 & 57.2 & 45.9 & 52.9 & 45.2 & 54.8 & 66.2 & 53.6 \\
\hline \multicolumn{11}{|l|}{ Residence } \\
\hline Rural & 40.7 & 31.2 & 41.5 & 59.6 & 43.1 & 41.0 & 28.5 & 48.2 & 62.2 & 44.3 \\
\hline Urban & 45.9 & 34.8 & 41.6 & 57.0 & 44.1 & 50.6 & 43.2 & 49.9 & 64.1 & 50.3 \\
\hline \multicolumn{11}{|c|}{ Age of child (months) } \\
\hline $0-11$ & 43.2 & 34.0 & 42.2 & 57.1 & 43.5 & 45.8 & 36.0 & 49.3 & 63.7 & 47.1 \\
\hline $12-23$ & 45.7 & 32.6 & 40.8 & 62.9 & 45.8 & 46.2 & 39.5 & 50.1 & 64.2 & 48.8 \\
\hline $24-35$ & 40.6 & 32.2 & 41.9 & 58.7 & 42.5 & 43.8 & 31.3 & 47.7 & 63.5 & 45.6 \\
\hline $36-59$ & 38.9 & 31.4 & 41.6 & 54.4 & 40.6 & 40.9 & 29.5 & 47.9 & 60.2 & 43.6 \\
\hline \multicolumn{11}{|l|}{ Birth order } \\
\hline 1 & 43.3 & 36.5 & 39.3 & 60.7 & 45.8 & 47.2 & 42.2 & 49.5 & 65.5 & 50.8 \\
\hline $2-3$ & 43.5 & 32.2 & 44.0 & 57.6 & 44.3 & 45.5 & 34.7 & 52.5 & 62.4 & 48.3 \\
\hline $4-5$ & 42.2 & 32.4 & 40.8 & 59.4 & 43.1 & 43.1 & 31.1 & 46.7 & 61.1 & 44.0 \\
\hline$>=6$ & 40.1 & 30.3 & 40.0 & 57.8 & 39.6 & 40.1 & 29.0 & 40.6 & 60.4 & 39.4 \\
\hline \multicolumn{11}{|c|}{ No of under-5 in household } \\
\hline$<=2$ & 42.9 & 34.2 & 42.6 & 59.1 & 45.0 & 44.3 & 36.4 & 49.5 & 64.1 & 48.2 \\
\hline$>=3$ & 41.6 & 29.2 & 37.0 & 57.7 & 39.4 & 43.8 & 29.0 & 45.2 & 53.3 & 40.4 \\
\hline
\end{tabular}

With respect to household relationship, Table 2 (right panel) showed that children of women in higher order polygynous unions recorded the poorest utilisation of health facility for ARI symptoms in WA (39.0\%) and CA (27.2\%). Again, health facility care-seeking was lowest among children whose mothers were wives $(41.7 \%)$ to household head in
WA and highest among those with mothers as household heads $(50.9 \%)$.

\section{Multivariable analyses}

Results from models fitted to investigate the independent effect of household relationship on healthcare seeking behaviour are presented in Table 3 (diarrhea) and 
Table 2 Household relationships among mothers of under-five children who sought care for diarrhea and ARI symptoms from health facilities in sub-Saharan Africa, 2012-2016

\begin{tabular}{|c|c|c|c|c|c|c|c|c|c|c|}
\hline \multirow[b]{2}{*}{ Variables } & \multicolumn{5}{|c|}{ Health facility care for diarrhea } & \multicolumn{5}{|c|}{ Health facility care for ARI symptoms } \\
\hline & $\begin{array}{l}\text { Western } \\
\text { Africa }\end{array}$ & $\begin{array}{l}\text { Central } \\
\text { Africa }\end{array}$ & $\begin{array}{l}\text { Eastern } \\
\text { Africa }\end{array}$ & $\begin{array}{l}\text { Southern } \\
\text { Africa }\end{array}$ & $\begin{array}{l}\text { sub-Saharan } \\
\text { Africa }\end{array}$ & $\begin{array}{l}\text { Western } \\
\text { Africa }\end{array}$ & $\begin{array}{l}\text { Central } \\
\text { Africa }\end{array}$ & $\begin{array}{l}\text { Eastern } \\
\text { Africa }\end{array}$ & $\begin{array}{l}\text { Southern } \\
\text { Africa }\end{array}$ & $\begin{array}{l}\text { sub-Saharan } \\
\text { Africa }\end{array}$ \\
\hline \multicolumn{11}{|l|}{ Maternal marital profile } \\
\hline Never married & 46.2 & 40 & 43.2 & 63 & 50.1 & 48.2 & 51 & 55.4 & 64.3 & 55.3 \\
\hline $\begin{array}{l}\text { First order marriage, } \\
\text { monogamy }\end{array}$ & 42.7 & 33.2 & 36.7 & 59.2 & 43.4 & 44.7 & 34.8 & 45.7 & 63.3 & 46.3 \\
\hline $\begin{array}{l}\text { First order marriage, } \\
\text { polygyny }\end{array}$ & 40.6 & 28.6 & 51.4 & 56.9 & 41.2 & 42.2 & 29.9 & 53.3 & 59.3 & 44.4 \\
\hline $\begin{array}{l}\text { Higher order marriage, } \\
\text { monogamy }\end{array}$ & 45.1 & 37.8 & 31.9 & 55.8 & 44.7 & 47.0 & 36.5 & 30.3 & 60.6 & 45.5 \\
\hline $\begin{array}{l}\text { Higher order marriage, } \\
\text { polygyny }\end{array}$ & 39.2 & 29.2 & 41.6 & 56.2 & 39.9 & 39 & 27.2 & 50.8 & 55.6 & 40.3 \\
\hline Formerly married & 44.4 & 31.4 & 41.7 & 58.6 & 44.3 & 44.4 & 28.7 & 50.1 & 64.7 & 46.9 \\
\hline \multicolumn{11}{|c|}{ Maternal relationship to household head } \\
\hline Head & 46.5 & 30.7 & 48.1 & 58.6 & 46.8 & 50.9 & 34.3 & 50.4 & 65.6 & 50.5 \\
\hline Wife & 40.1 & 32.6 & 41.7 & 58.5 & 42 & 41.7 & 33.6 & 48.2 & 61.3 & 44.4 \\
\hline Daughter/in-law & 47.2 & 32.5 & 35.4 & 60.3 & 45.5 & 46.7 & 34.2 & 48.7 & 61 & 47.5 \\
\hline Others & 48.7 & 36.2 & 34.5 & 59.8 & 46.7 & 50.2 & 36.8 & 49.1 & 71.5 & 51.7 \\
\hline
\end{tabular}

Table 4 (ARI symptoms). Even though, explanatory models which include all variables were fitted, we present results for only household relationship which is the primary focus of this study. Odds Ratio from unadjusted and adjusted models was quite similar. Table 3 (panel 2) shows that most of the variables did not attain statistical significance in their association with healthcare seeking behaviour for childhood diarrhea. Higher order monogamy was associated with lower odds of health facility care for diarrhea in Western Africa (OR = 0.89, CI: 0.78-1.03). In Eastern Africa, mothers who never married $(\mathrm{OR}=1.43, \mathrm{CI}$ : $0.97-2.11)$ and those in first order polygynous unions $(\mathrm{OR}=1.19, \mathrm{CI}$ : $0.89-1.57$ ) were more likely to seek health facility care for childhood diarrhea. Compared to housewives, daughters/ daughters-in-laws were significantly less likely of taking their children to health facility for appropriate diarrhea treatment (OR $=0.86, \mathrm{CI}: 0.51-0.95)$.

Results for ARI symptoms (Table 4, panel 2) shows that formerly married women in WA $(\mathrm{AOR}=0.83, \mathrm{CI}$ : 0.65-1.07), CA (AOR $=0.82, \mathrm{CI}: 0.63-1.06)$ and SA (AOR $=0.86, \mathrm{CI}: 0.66-1.13)$ were less likely of seeking healthcare for child ARI symptoms from health facility compared to women in first order monogamous marriages. In addition, higher order polygyny was associated with lower odds of health facility care for ARI symptoms in WA $(\mathrm{AOR}=0.86, \mathrm{CI}: 0.71-1.05)$, $\mathrm{CA}(\mathrm{AOR}=0.82, \mathrm{CI}$ : $0.63-1.07)$ and SA (AOR $=0.71, \mathrm{CI}: 0.50-1.00)$. Having a mother who is the head of household was significantly associated with higher odds of facility care for ARI symptoms in children from Western Africa $(\mathrm{AOR}=1.20$,
CI: 1.02-1.43) and Southern Africa $(\mathrm{AOR}=1.49$, CI: $1.20-1.85)$.

\section{Discussion}

We explored the influence of household relationships on healthcare seeking behaviour for diarrhea and symptoms of ARI - two leading childhood illnesses in sub-Saharan Africa regions. Our results showed that less than half of mothers of children affected by diarrhea and ARI symptoms sought care from health facility. These levels of healthcare utilisation represent some improvement when compared to the situation about a decade ago [38]. There are different pathways to care-seeking for childhood illnesses by mothers of under-fives in the region. In many sub-Saharan Africa settings, the common practice is home management and spiritual / traditional healers before health facility treatment [26, 30]. This healthcare seeking behaviour is often linked to perceptions about causes of illnesses and source(s) of solution [15, 39]. When there is a belief that illness in a child is caused by some spiritual forces or due to violation of certain traditional norms, the parents are more likely to seek healthcare from a traditional healer who they believe knows how to appease the gods [40]. Lowest uptake of health facility care for diarrhea and ARI symptoms in Central Africa possibly explains why the sub-region ranks high in childhood mortality in sub-Saharan Africa. Congo DR, the largest country in the sub-region is recovering gradually from a conflict situation. Communities ravaged by internal 
Table 3 Unadjusted and adjusted effect of household relationships on health seeking behaviour for childhood diarrhea in subSaharan Africa, 2012-2016

\begin{tabular}{|c|c|c|c|c|c|}
\hline \multirow[b]{2}{*}{ Caregiver characteristics } & \multicolumn{5}{|c|}{ Unadjusted Odds Ratio (OR) } \\
\hline & Western Africa & Middle Africa & Eastern Africa & Southern Africa & sub-Saharan Africa \\
\hline \multicolumn{6}{|l|}{ Marital profile } \\
\hline Never married & $0.99(0.84-1.18)$ & $0.98(0.78-1.25)$ & $1.17(0.86-1.60)$ & $1.02(0.83-1.26)$ & $1.01(0.91-1.13)$ \\
\hline First order marriage, monogamy & 1.00 & 1.00 & 1.00 & 1.00 & 1.00 \\
\hline First order marriage, polygyny & $0.94(0.86-1.02)$ & $0.87(0.77-1.00)$ & $0.98(0.84-1.15)$ & $0.86(0.71-1.05)$ & $0.92(0.87-0.98)^{*}$ \\
\hline Higher order marriage, monogamy & $0.88(0.77-1.01)$ & $1.08(0.91-1.27)$ & $0.99(0.74-1.33)$ & $0.85(0.72-1.00)$ & $0.92(0.8401 .01)$ \\
\hline Higher order marriage, polygyny & $0.89(0.77-1.04)$ & $0.94(0.76-1.17)$ & $0.82(0.60-1.11)$ & $0.78(0.60-1.02)$ & $0.88(0.79-0.97)^{*}$ \\
\hline Formerly married & $0.88(0.73-1.06)$ & $0.93(0.75-1.14)$ & $1.09(0.85-1.42)$ & $0.90(0.75-1.09)$ & $0.92(0.84-1.02)$ \\
\hline \multicolumn{6}{|l|}{ Relationship to household head } \\
\hline Head & $1.04(0.92-1.19)$ & $0.92(0.78-1.09)$ & $0.88(0.74-1.05)$ & $1.08(0.92-1.26)$ & $0.99(0.92-1.07)$ \\
\hline Wife & 1.00 & 1.00 & 1.00 & 1.00 & 1.00 \\
\hline Daughter/in-law & $1.10(0.99-1.23)$ & $0.99(0.78-1.09)$ & $0.80(0.63-1.01)$ & $1.06(0.89-1.25)$ & $1.03(0.95-1.11)$ \\
\hline \multirow[t]{2}{*}{ Others } & $1.02(0.89-1.16)$ & $1.03(0.83-1.27)$ & $0.76(0.53-1.09)$ & $1.10(0.87-1.38)$ & $1.00(0.91-1.11)$ \\
\hline & Adjusted OR ${ }^{++}$ & & & & \\
\hline \multicolumn{6}{|l|}{ Caregiver marital profile } \\
\hline Never married & $0.97(0.81-1.15)$ & $0.97(0.76-1.23)$ & $1.43(0.97-2.11)$ & $1.00(0.81-1.24)$ & $1.00(0.89-1.12)$ \\
\hline First order marriage, monogamy & 1.00 & 1.00 & 1.00 & 1.00 & 1.00 \\
\hline First order marriage, polygyny & $0.99(0.91-1.09)$ & $0.92(0.80-1.05)$ & $1.19(0.89-1.57)$ & $0.88(0.73-1.07)$ & $0.98(0.91-1.04)$ \\
\hline Higher order marriage, monogamy & $0.89(0.78-1.03)$ & $1.09(0.92-1.30)$ & $1.05(0.78-1.42)$ & $0.88(0.74-1.05)$ & $0.95(0.87-1.04)$ \\
\hline Higher order marriage, polygyny & $0.95(0.81-1.09)$ & $0.98(0.79-1.22)$ & $0.82(0.49-1.39)$ & $0.83(0.64-1.09)$ & $0.94(0.84-1.04)$ \\
\hline Formerly married & $0.90(0.75-1.09)$ & $0.95(0.78-1.18)$ & $1.11(0.80-1.52)$ & $0.93(0.76-1.13)$ & $0.95(0.86-1.06)$ \\
\hline \multicolumn{6}{|l|}{ Relationship to household head } \\
\hline Head & $1.03(0.90-1.17)$ & $0.93(0.79-1.10)$ & $0.81(0.65-1.00)$ & $1.08(0.92-1.27)$ & $0.99(0.92-1.08)$ \\
\hline Wife & 1.00 & 1.00 & 1.00 & 1.00 & 1.00 \\
\hline Daughter/in-law & $1.06(0.95-1.19)$ & $0.97(0.81-1.15)$ & $0.81(0.51-0.95)^{*}$ & $1.04(0.84-1.24)$ & $0.99(0.92-1.08)$ \\
\hline Others & $0.99(0.86-1.14)$ & $1.02(0.82-1.27)$ & $0.90(0.86-1.71)$ & $1.06(0.84-1.36)$ & $0.99(0.90-1.10)$ \\
\hline \multicolumn{6}{|l|}{ Random effects parameters } \\
\hline Country: Variance (SE) & $0.3789(0.1613)$ & $0.0229(0.0234)$ & $15.6738(14.5082)$ & $0.1421(0.0964)$ & $1.6615(0.5506)$ \\
\hline Community: Variance (SE) & $0.1765(0.0278)$ & $0.2043(0.0416)$ & $0.0647(0.0386)$ & $0.0876(0.0235)$ & $0.1507(0.0164)$ \\
\hline \multicolumn{6}{|l|}{ Model parameters } \\
\hline Log-likelihood & -9717.6826 & -5193.6512 & -1895.0743 & -4858.7665 & -2176.202 \\
\hline Wald statistic & 175.33 & 95.04 & 36.16 & 79.28 & 269.88 \\
\hline$p$-value & $<0.001$ & $<0.001$ & 0.0888 & $<0.001$ & $<0.001$ \\
\hline
\end{tabular}

${ }^{*} p<0.05$ based on models adjusted for demographic and socio-economic characteristics

conflicts and displacements suffer enormous deterioration in terms of health facilities [41, 42].

Furthermore, comparison of unadjusted and adjusted measures of association between household relationship and healthcare seeking behaviour showed very little differences. This implies that demographic and socio-economic factors do not necessarily explain the influence of household relationships. The roles of intra-household relationship in healthcare utilisation are not mediated by prevailing socio-economic status. The finding implied that household social environment cannot be subsumed under socio-economic factors as far as child healthcare utilisation is concerned.

Although not statistically significant, household relationships showed stronger association with care-seeking behaviour for treatment of ARI symptoms than diarrhea. This is similar to evidence from an assessment of child health inequality conducted by the WHO which revealed 
Table 4 Unadjusted and adjusted effect of household relationships on health seeking behaviour for ARI symptoms among underfives in sub-Saharan Africa, 2012-2016

\begin{tabular}{|c|c|c|c|c|c|}
\hline \multirow[b]{2}{*}{ Caregiver characteristics } & \multicolumn{5}{|l|}{ Unadjusted OR } \\
\hline & Western Africa & Middle Africa & Eastern Africa & Southern Africa & sub-Saharan Africa \\
\hline \multicolumn{6}{|l|}{ Marital profile } \\
\hline Never married & $1.02(0.81-1.29)$ & $1.19(0.89-1.59)$ & $1.15(0.84-1.58)$ & $0.91(0.68-1.20)$ & $1.09(0.95-1.25)$ \\
\hline First order marriage, monogamy & 1.00 & 1.00 & 1.00 & 1.00 & 1.00 \\
\hline First order marriage, polygyny & $0.96(0.85-1.08)$ & $0.86(0.73-1.02)$ & $0.87(0.75-1.02)$ & $0.88(0.69-1.13)$ & $0.90(0.84-0.97)^{*}$ \\
\hline Higher order marriage, monogamy & $0.88(0.74-1.04)$ & $0.79(0.64-0.97)^{*}$ & $0.89(0.62-1.27)$ & $0.84(0.67-1.06)$ & $0.85(0.76-0.95)^{*}$ \\
\hline Higher order marriage, polygyny & $0.82(0.68-0.99)^{*}$ & $0.79(0.60-1.02)$ & $1.04(0.76-1.44)$ & $0.65(0.46-0.91)^{*}$ & $0.82(0.72-0.93)^{*}$ \\
\hline Formerly married & $0.81(0.63-1.04)$ & $0.79(0.61-1.02)$ & $1.02(0.79-1.33)$ & $0.84(0.64-1.09)$ & $0.89(0.78-1.00)$ \\
\hline \multicolumn{6}{|l|}{ Relationship to household head } \\
\hline Head & $1.04(0.92-1.19)$ & $0.92(0.78-1.09)$ & $0.88(0.74-1.05)$ & $1.08(0.92-1.26)$ & $1.13(1.03-1.24)^{*}$ \\
\hline Wife & 1.00 & 1.00 & 1.00 & 1.00 & 1.00 \\
\hline Daughter/in-law & $1.10(0.99-1.23)$ & $0.99(0.84-1.17)$ & $0.80(0.63-1.01)$ & $1.06(0.90-1.25)$ & $1.02(0.93-1.12)$ \\
\hline \multirow[t]{2}{*}{ Others } & $1.02(0.89-1.16)$ & $1.03(0.83-1.27)$ & $0.76(0.53-1.09)$ & $1.10(0.87-1.38)$ & $1.17(1.03-1.33)^{*}$ \\
\hline & Adjusted $\mathrm{OR}^{++}$ & & & & \\
\hline \multicolumn{6}{|l|}{ Caregiver marital profile } \\
\hline Never married & $0.92(0.72-1.17)$ & $1.14(0.85-1.54)$ & $1.07(0.71-1.61)$ & $0.86(0.65-1.15)$ & $1.01(0.88-1.17)$ \\
\hline First order marriage, monogamy & 1.00 & 1.00 & 1.00 & 1.00 & 1.00 \\
\hline First order marriage, polygyny & $1.00(0.88-113)$ & $0.92(0.77-1.09)$ & $0.79(0.58-1.09)$ & $0.94(0.73-1.21)$ & $0.98(0.89-1.07)$ \\
\hline Higher order marriage, monogamy & $0.92(0.78-1.10)$ & $0.82(0.66-1.01)$ & $0.97(0.67-1.41)$ & $0.90(0.71-1.14)$ & $0.89(0.80-1.00)$ \\
\hline Higher order marriage, polygyny & $0.86(0.71(1.05)$ & $0.82(0.63-1.07)$ & $1.12(0.66-1.89)$ & $0.71(0.50-1.00)$ & $0.85(0.74-0.98)^{*}$ \\
\hline Formerly married & $0.83(0.65-1.07)$ & $0.82(0.63-1.06)$ & $1.00(0.71-1.40)$ & $0.86(0.66-1.13)$ & $0.91(0.79-1.04)$ \\
\hline \multicolumn{6}{|l|}{ Relationship to household head } \\
\hline Head & $1.20(1.02-1.43)^{*}$ & $1.04(0.85-1.27)$ & $1.04(0.82-1.32)$ & $1.49(1.20-1.85)^{*}$ & $1.17(1.06-1.29)$ \\
\hline Wife & 1.00 & 1.00 & 1.00 & 1.00 & 1.00 \\
\hline Daughter/in-law & $0.94(0.81-1.09)$ & $0.92(0.74-1.13)$ & $0.94(0.67-1.31)$ & $1.17(0.93-1.49)$ & $0.95(0.86-1.05)$ \\
\hline Others & $0.99(0.82-1.18)$ & $0.97(0.72-1.29)$ & $1.62(0.96-2.74)$ & $1.89(1.35-2.66)^{*}$ & $1.11(0.97-1.27)$ \\
\hline \multicolumn{6}{|l|}{ Random effects parameters } \\
\hline Country: Variance (SE) & $0.2739(0.1219)$ & $0.06305(0.05523)$ & $13.8080(12.8859)$ & $0.1689(0.1143)$ & $1.3434(0.4517)$ \\
\hline Community: Variance (SE) & $0.2821(0.0502)$ & $0.17749(0.0460)$ & $0.1781(0.0551)$ & $0.0569(0.0247)$ & $0.1861(0.0231)$ \\
\hline \multicolumn{6}{|l|}{ Model parameters } \\
\hline Log-likelihood & -5476.2264 & -3326.2409 & -1767.8458 & -2651.6569 & $-13,310.475$ \\
\hline Wald statistic & 148.32 & 132.1 & 67.46 & 88.94 & 324.54 \\
\hline $\mathrm{p}$-value & $<0.001$ & $<0.001$ & $<0.001$ & $<0.001$ & $<0.001$ \\
\hline
\end{tabular}

${ }^{*} p<0.05 ;++$ based on models adjusted for demographic and socio-economic characteristics

that the magnitude of inequality in treatment of ARI symptoms was greater than that of diarrhea [38]. Though it is nearly impossible to unravel the reasons for these differences using the data analysed, it suggests that the effect of household relationship on care-seeking behaviour depend on the specific health condition. Perception of illness causes and navigation of treatment options have been suggested to vary across household and communities [27].
Having a mother who is daughter/daughter-in-law to head of household was associated with lesser chances of health facility care for childhood diarrhea in Eastern Africa. Concerning daughters/daughters-in-laws, socio-cultural norms in many sub-Saharan Africa contexts demand that they defer to their parents or parents-in-law in decision-making on child healthcare. Ethnographic data from Northern Ghana actually confirms grandmothers as sources of social support for young mothers [29]. In their 
roles as guardians, they often favour seeking treatment from traditional healers thereby discouraging the use of health facilities [29].

In regard to care-seeking for ARI symptoms, though the direction of relationship is similar across the four sub-regions, the magnitude varied. These differences might be due to variables related to health system which is not uniform across settings. Examples of such variables include child survival interventions implemented by different countries, doctors per population, user fees, and health insurance coverage among others.

Western and Southern Africa mothers who were household heads were significantly more likely of seeking health facility care for ARI symptoms. There are evidences in literature that supports this finding [43, 44]. Mothers of under-five children who also doubled as heads of their households clearly do not experience the problem of getting permission to seek care which is a common barrier to healthcare utilisation for women and children [26, 30, 45]. In addition, such women would most likely not want to take any risk since there is no other person playing the headship role in the household. This finding does not suggest that advocacy be made for mothers of under-five children to become household heads. Rather, it implies that they should be given more freedom to take proactive decisions on child healthcare.

This study has some limitations. Both diarrhea and ARI symptoms were based on maternal reports about the child health condition within two weeks of the interviews. While the problem of recall may be minimal, some women may not have correctly recognised the signs and symptoms of ARI. Inaccurate recognition of ARI symptoms have been reported in some studies [3, 46]. In addition, these health conditions were not based on any medical diagnosis. Therefore, over or under-reporting may not be completely ruled out. Another limitation is the inability to analyse health system/service related factors that may be related to child healthcare seeking behaviour.

One strength of this study is our use of appropriate statistical techniques which accounts for inter country variations. Besides, the study served the purpose of presenting stronger and nationally representative findings to complement evidence from few qualitative studies on intra household dynamics and child healthcare utilisation in SSA.

Our findings have implications for future research and programmes on child health and survival. Further studies are needed to provide innovative strategies on how male household heads can be motivated to proactively support utilisation of healthcare services for children. Apart from women, stronger child health advocacy and awareness targeted at men in Western Africa are needed in view of their roles in household leadership and provision of resources for children healthcare.

\section{Conclusion}

With less than half of affected children receiving care for diarrhea and ARI symptoms from health facilities, care-seeking for treatable causes of childhood death is still below average in sub-Saharan Africa. Though, there are subtle variations in magnitude, the pattern and direction of association with household relationship is consistent across the four sub-regions. Different dimensions of household relationships such as polygyny, higher order marriages, being formerly married and being a daughter or daughter-in-law by a mother of under-five are not associated with healthcare seeking behaviour for childhood diarrhea and ARI symptoms. However, mothers who served as household head in Western and Southern Africa were more likely to seek health facility care for ARI symptoms. Statistical non-significance in the other two sub-regions is an indication that household relationship is not a barrier to care-seeking from health facilities.

\section{Additional file}

Additional file 1: Table S1. List of study countries, survey year and weighted sample size. A table showing study countries, survey year and weighted sample size. (DOCX $15 \mathrm{~kb}$ )

\section{Abbreviations \\ AOR: Adjusted Odds Ratio; ARI: Acute respiratory tract infections; CA: Central Africa; Cl: Confidence Interval; DHS: Demographic and Health Survey; DV: Dependent variable; EA: Eastern Africa; IV: Independent variable; OR: Odds Ratio; SA: Southern Africa; SDG: Sustainable Development Goal; SSA: Sub-Saharan Africa; WA: Western Africa; WHO: World Health Organization}

\section{Acknowledgements}

The DHS Program, implementing agencies in different countries are acknowledged for making the data available for further analysis. A preliminary version of this paper was presented at the 2016 Annual conference of the Population Association of Southern Africa in

Johannesburg, South Africa. Authors appreciate the comments from participants at the session where the paper was presented. This work is based on research supported in part by the National Research Foundation of South Africa (Grant Numbers: 105931).

\section{Funding}

Not applicable.

Availability of data and materials

The datasets analysed for the current study are available in the Measure DHS program repository [34].

\section{Authors' contributions}

Conceptualisation, study design, data retrieval, analysis and interpretation, drafting of manuscript [JOA]. Literature review [PB]. Revision of intellectual content of manuscript [ND, AEA, CO]. All authors read and approved the final manuscript. 


\section{Ethics approval and consent to participate}

No ethical approval was needed because anonymised secondary data archived by the DHS program was analysed. Prior to data collection in respective countries, the DHS program and country partners sought ethical approval from relevant authorities. DHS questionnaires and protocols are reviewed by the ICF Institutional Review Board [47] to ensure compliance with the U.S. Department of Health and Human Services regulations for the protection of human subjects (45 CFR 46). In addition, informed consent was taken before respondents were interviewed. No identifying information was collected during fieldwork; neither did the processed data contain items of information that could compromise privacy and confidentiality of survey participants. Formal approval to analyse the data was granted by the DHS program.

\section{Consent for publication}

Not applicable

\section{Competing interests}

Authors declare that they have no competing interests.

\section{Publisher's Note}

Springer Nature remains neutral with regard to jurisdictional claims in published maps and institutional affiliations.

\section{Author details}

'Demography and Population Studies Programme, Schools of Public Health and Social Sciences, University of the Witwatersrand, Johannesburg, South Africa. ${ }^{2}$ Department of Epidemiology and Medical Statistics, Faculty of Public Health, College of Medicine, University of Ibadan, Ibadan, Nigeria.

${ }^{3}$ Department of Sociology, Covenant University, Ota, Nigeria.

\section{Received: 15 November 2018 Accepted: 2 May 2019}

\section{Published online: 14 May 2019}

\section{References}

1. Liu L, Oza S, Hogan D, Perin J, Rudan I, Lawn JE, et al. Global, regional, and national causes of child mortality in 2000-13, with projections to inform post-2015 priorities: an updated systematic analysis. Lancet. 2015;385:430-40.

2. Walker CLF, Rudan I, Liu L, Nair H, Theodoratou E, Bhutta ZA, et al. Global burden of childhood pneumonia and diarrhoea. Lancet. 2013;381:1405-16.

3. Deldsetzer P, T.C. W, Kirolos A, Mitchell S, Ratcliffe LA, M.K. K-L, et al. The recognition of and care seeking behaviour for childhood illness in developing countries: a systematic review. PLoS One 2014;9(4):e93427.

4. Jhamba T, Mmatli K. Households and family dynamics in South Africa. In: Odimegwu C, Kekovole J, editors. Social demography of South Africa. New York: Routledge; 2016

5. Khan S. Changing family forms, patterns and emerging challenges within the south African Indian diaspora. J Comp Fam Stud. 2012;43(1):133-50.

6. Scott ME, Wilcox WB, Ryberg R, DeRose L. Mapping family change and child well-being outcomes. New York: Social Trends Institute; 2015.

7. Osborne C, Berger LM, Magnuson K. Family structure transitions and changes in maternal resources and well-being. Demography. 2012;49(1):23-47.

8. Rasmussen AW. Family structure changes and Children's health, behavior, and educational outcomes. 2009.

9. Aremu O, Lawoko S, Moradi T, D K. Socio-economic determinants in selecting childhood diarrhoea treatment options in sub- Saharan Africa: a multilevel model. Ital J Paediatr. 2011;37:13.

10. Kandala NB, Emina JB, Nzita PD, Cappuccio FP. Diarrhoea, acute respiratory infection, and fever among children in the Democratic Republic of Congo. Soc Sci Med. 2009;68(9):1728-36 Epub 2009/03/17.

11. Kandala NB, Ji C, Stallard N, Stranges S, Cappuccio FP. Morbidity from diarrhoea, cough and fever among young children in Nigeria. Ann Trop Med Parasitol. 2008;102(5):427-45 Epub 2008/06/26.

12. Akinyemi JO, Bamgboye EA, Ayeni O. New trends in under-five mortality determinants and their effects on child survival in Nigeria: a review of childhood mortality data from 1990-2008. Afr Popul Stud. 2013;27(1):25-42.

13. Abdulkadir MB, Abdulkadir ZA. A cross-sectional survey of parental careseeking behavior for febrile illness among under-five children in Nigeria. Alex J Med. 2017;53(1):85-91.

14. Adinan J, Damian DJ, Mosha NR, Mboya IB, Mamseri R, Msuya SE. Individual and contextual factors associated with appropriate healthcare seeking behavior among febrile children in Tanzania. PLoS One. 2017;12(4):e0175446 Epub 2017/04/14

15. Noordam AC, Carvajal-Velez L, Sharkey AB, Young M, Cals JW. Care seeking behaviour for children with suspected pneumonia in countries in sub-Saharan Africa with high pneumonia mortality. PLoS One. 2015;10(2): e0117919 Epub 2015/02/24.

16. Astale T, Chenault M. Help-seeking behavior for children with acute respiratory infection in Ethiopia: results from 2011 Ethiopia demographic and health survey. PLoS One. 2015;10(11):e0142553 Epub 2015/11/13.

17. Quansah E, Ohene LA, Norman L, Mireku MO, Karikari TK. Social factors influencing child health in Ghana. PLoS One. 2016;11(1):e0145401 Epub 2016/01/09.

18. Ustrup M, Ngwira B, Stockman $\sqcup$, Deming M, Nyasulu P, Bowie C, et al. Potential barriers to healthcare in Malawi for under-five children with cough and fever: a national household survey. J Health Popul Nutr. 2014;32(1):6878 Epub 2014/05/23.

19. Kassile T, Lokina R, Mujinja P, Mmbando BP. Determinants of delay in care seeking among children under five with fever in Dodoma region, Central Tanzania: a cross-sectional study. Malar J. 2014;13:348 Epub 2014/09/04.

20. Franckel A, Lalou R. Health-seeking behaviour for childhood malaria: household dynamics in rural Senegal. J Biosoc Sci. 2009;41(1):1-19 Epub 2008/06/14.

21. Richards E, Theobald S, George A, Kim JC, Rudert C, Jehan K, et al. Going beyond the surface: gendered intra-household bargaining as a social determinant of child health and nutrition in low and middle income countries. Soc Sci Med. 2013;95:24-33 Epub 2012/07/20.

22. Koffi AK, Kalter HD, Loveth EN, Quinley J, Monehin J, Black RE. Beyond causes of death: the social determinants of mortality among children aged 1-59 months in Nigeria from 2009 to 2013. PLoS One. 2017;12(5):e0177025 Epub 2017/06/01.

23. Turney $\mathrm{K}$, Lee $\mathrm{H}$, Mehta $\mathrm{N}$. The social determinants of child health. Soc Sci Med. 2013:95:1-5.

24. Rutherford ME, Mulholland K, Hill PC. How access to health care relates to under-five mortality in sub-Saharan Africa: systematic review. Tropical Med Int Health. 2010;15(5):508-19 Epub 2010/03/30.

25. Abubakar A, Van Baar A, Fischer R, Bomu G, Gona JK, Newton CR. Socio-cultural determinants of health-seeking behaviour on the Kenyan coast: a qualitative study. PLoS One. 2013;8(11):e71998 Epub 2013/11/22.

26. Bedford KJ, Sharkey AB. Local barriers and solutions to improve care-seeking for childhood pneumonia, diarrhoea and malaria in Kenya, Nigeria and Niger: a qualitative study. PLoS One. 2014;9(6):e100038 Epub 2014/06/28.

27. Scott K, McMahon S, Yumkella F, Diaz T, George A. Navigating multiple options and social relationships in plural health systems: a qualitative study exploring healthcare seeking for sick children in Sierra Leone. Health Policy Plan. 2014;29(3):292-301. Epub 2013/03/29.

28. Tolhurst R, Amekudzi YP, Nyonator FK, Bertel Squire S, Theobald S. "he will ask why the child gets sick so often": the gendered dynamics of intrahousehold bargaining over healthcare for children with fever in the Volta region of Ghana. Soc Sci Med. 2008:66(5):1106-17 Epub 2008/01/02.

29. Gupta ML, Aborigo RA, Adongo PB, Rominski S, Hodgson A, Engmann CM et al. Grandmothers as gatekeepers? The role of grandmothers in influencing health-seeking for mothers and newborns in rural northern Ghana. Glob Public Health. 2015;10(9):1078-91. Epub 2015/01/31.

30. Charles JO, Udonwa NE, Ikoh MU, Ikpeme BI. The role of mothers in household health-seeking behavior and decision-making in childhood febrile illness in Okurikang/lkot Effiong Otop community, Cross River state, Nigeria. Health Care Women Int. 2008;29(8):906-25 Epub 2008/08/30.

31. Costello AM, Dalglish SL. On behalf of the strategic review study team. In: Towards a grand convergence for child survival and health: a strategic review of options for the future building on lessons learnt from IMNCI. Geneva: World Health Organization; 2016.

32. Rudan I, El Arifeen S, Bhutta ZA, Black RE, Brooks A, Chan KY, et al. Setting research priorities to reduce global mortality from childhood pneumonia by 2015. PLoS Med. 2011:8(9):e1001099 Epub 2011/10/08.

33. Schoumaker B. Quality and consistency of DHS fertility estimates, 1990 to 2012. Rockville, Maryland, USA: ICF International; 2014.

34. The DHS Program. Available Datasets. 2015 [cited 201510 August];Available from: https://dhsprogram.com/data/available-datasets.cfm.

35. Andersen RM. National health surveys and the behavioral model of health services use. Med Care. 2008;46(7):647-53 Epub 2008/06/27.

36. Andersen RM. Revisiting the behavioral model and access to medical care: does it matter? J Health Soc Behav. 1995:36(1):1-10 Epub 1995/ 03/01. 
37. Romay-Barja M, Jarrin I, Ncogo P, Nseng G, Sagrado MJ,

Santana-Morales MA, et al. Rural-urban differences in household treatmentseeking behaviour for suspected malaria in children at Bata District, Equatorial Guinea. PLoS One. 2015;10(8):e0135887 Epub 2015/08/19.

38. State of inequality: reproductive, maternal, newborn and child health. Geneva: world health Orgnization: World Health Organization; 2015.

39. Page AL, Hustache S, Luquero FJ, Djibo A, Manzo ML, Grais RF. Health care seeking behavior for diarrhea in children under 5 in rural Niger: results of a cross-sectional survey. BMC Public Health. 2011;11:389 Epub 2011/05/27.

40. Tinuade O, lyabo RA, Durotoye O. Health-care-seeking behaviour for childhood illnesses in a resource-poor setting. J Paediatr Child Health. 2010; 46(5):238-42 Epub 2010/03/27.

41. Omba Kalonda JC. Socioeconomic impact of armed conflict on the health of women and children in the Democratic Republic of the Congo. Med Trop (Mars). 2011;71(2):192-6 Epub 2011/06/24. Impact socio-economique du conflit en Republique Democratique du Congo sur la sante des femmes et des enfants.

42. Rossi L, Hoerz T, Thouvenot V, Pastore G, Michael M. Evaluation of health, nutrition and food security programmes in a complex emergency: the case of Congo as an example of a chronic post-conflict situation. Public Health Nutr. 2006;9(5):551-6 Epub 2006/08/23.

43. Gupta AK, Bortkotoky K, Kumar A. Household headship and infant mortality in India: evaluating the determinants and differentials. Int J MCH AIDS. 2015; 3(1):44-52.

44. Gurmu E, Etana E. Household structure and children's nutritional status in Ethiopia. GENUS. 2013:69(2):113-30

45. Carlson GJ, Kordas K, Murray-Kolb LE. Associations between women's autonomy and child nutritional status: a review of the literature. Matern Child Nutr. 2015;11(4):452-82 Epub 2014/02/14.

46. Kamat VR. "I thought it was only ordinary fever!" cultural knowledge and the micropolitics of therapy seeking for childhood febrile illness in Tanzania. Soc Sci Med. 2006;62(12):2945-59 Epub 2006/01/13.

47. The DHS Program. Protecting the Privacy of DHS Survey Respondents. 2017 [cited 201714 September]; Available from: http://dhsprogram.com/WhatWe-Do/Protecting-the-Privacy-of-DHS-Survey-Respondents.cfm.

Ready to submit your research? Choose BMC and benefit from:

- fast, convenient online submission

- thorough peer review by experienced researchers in your field

- rapid publication on acceptance

- support for research data, including large and complex data types

- gold Open Access which fosters wider collaboration and increased citations

- maximum visibility for your research: over $100 \mathrm{M}$ website views per year

At $\mathrm{BMC}$, research is always in progress.

Learn more biomedcentral.com/submissions 